\title{
Estratégias editoriais de barateamento do livro: o caso dos romances vendidos em fascículos
}

\author{
Editorial strategies to reduce book costs: novels sold in booklet form \\ Valéria AUGUSTI* \\ Universidade Federal do Pará (UFPA)
}

\begin{abstract}
RESUMO: Este artigo tem por objetivo discutir as práticas editoriais implicadas na publicação de coleções de romances vendidos em fascículos. Para tanto, tem como corpus privilegiado de análise paratextos editoriais que acompanham exemplares de prosa de ficção francesa traduzidos e publicados por tipógrafos e editores portugueses no Oitocentos. As características do suporte material e o sistema de vendas por assinatura são testemunhos das estratégias editoriais implicadas no processo de barateamento do livro no século XIX. Por consequência, a análise do repertório de obras publicadas em fascículos permite escrever uma história da literatura do ponto de vista de certo tipo de leitor: aquele cujos parcos recursos financeiros não permitiam entrar em uma livraria e sair com um livro impresso nas mãos.
\end{abstract}

PALAVRAS-CHAVE: Romances. Fascículos. Coleções editoriais. Século XIX

ABSTRACT: This article seeks to discuss the editorial practices involved in publishing romance collections sold in booklet form. To do so, editorial paratexts, which accompany French fiction translated and published by Portuguese publishing houses and printers in the nineteenth century, were analyzed. The characteristics of support materials and the system of sales based on subscriptions are testimony to the editorial strategies involved in the process of lowing the book costs in the nineteenth century. Consequently, analyzing the repertoire of works published in booklets allows us to write a history of literature from the perspective of a certain type of reader: those whose sparse financial resources did not allow them to enter a book store and purchase a printed book.

KEYWORDS: Novels. Booklet. Editorial collections. 19th century

\footnotetext{
* Doutora em Teoria e História Literária (UNICAMP). Professora da Faculdade de Letras (FALE) da Universidade Federal do Pará e do Programa de Pós-graduação em Letras da UFPA. E-mail: augustivaleria@gmail.com
}

Revista Moara, n. 52, jan-jul 2019 ISSN: 0104-0944

Recebido em 10/04/2019

Avaliado em 09/05/2019 


\section{Introdução}

Não é possível discutir o sucesso do gênero romance junto ao público leitor Oitocentista sem, necessariamente, abordar a problemática dos suportes materiais pelos quais foi dado a ler. A circulação no formato códex parece não ter sido capaz de garantir o acesso generalizado a esse gênero literário que, desde pelo menos o século XVIII, agradava a um público leitor cada vez mais amplo. O sucesso do romance-folhetim no século XIX, ou seja, do romance publicado aos pedaços nos rodapés de jornais e revistas, evidencia o fato de que havia parcelas do público leitor para as quais adquirir um volume ainda era algo por demais custoso do ponto de vista financeiro. Se para esses leitores comprar um romance na íntegra, publicado no formato códex, parece ter sido inviável, o mesmo não se pode dizer do pagamento periódico de valores diminutos capazes de garantir, ao final de certo período, a leitura da totalidade de um texto ficcional. No Brasil, a importância do romance-folhetim, cuja literatura está vastamente estabelecida, parece ter obliterado o debate sobre outra modalidade de publicação de prosa ficcional em frações, qual seja, aquela da venda em fascículos. É dessa modalidade de publicação que tratará este artigo. Antes, porém, é necessário ter clareza sobre o que significa o termo fascículo e como serviu historicamente à venda de romances.

\section{Coleções portuguesas de romances vendidos em fascículos}

O termo fascículo pode ser definido como um caderno ou grupo de cadernos que fazem parte de uma obra publicada em "livraison", ou seja, entregue mediante encomenda. Esses cadernos de livros vendidos em frações são destinados a encontrar sua totalidade em um volume quando o conjunto dos cadernos previstos tiver sido publicado. É importante assinalar que o pagamento da obra se dá também de forma parcelada, uma vez que o leitor compra os cadernos em separado, mediante assinatura, para reuni-los ao final. Como é possível perceber, essa modalidade de publicação aproxima o livro do universo da imprensa em virtude do fato de os cadernos serem lançados periodicamente e vendidos, via de regra, a preços acessíveis. Compreende-se, então, a finalidade que presidiu o surgimento dessa fórmula de venda: permitir aos Revista Moara, n. 52, jan-jul 2019 ISSN: 0104-0944 
extratos sociais com poucos recursos financeiros adquirir aos pedaços e a preços baixos as obras que não poderiam comprar de uma só vez (DICTIONNAIRE ENCYCLOPEDIQUE DU LIVRE, 2005, p.183).

Ainda que a modalidade de venda em fascículos tenha surgido na França e Inglaterra no século XVIII, foi no século seguinte que ela conheceu uma forte expansão, sobretudo em virtude do processo de alfabetização em massa, que aumentou significativamente a quantidade de leitores. Editores e livreiros passaram, então, a refletir sobre a possibilidade de adaptar seus produtos a um público de baixa renda, muitas vezes atraído pela leitura do romance-folhetim, garantida pela redução do preço dos jornais, que deixaram de ser vendidos exclusivamente por assinatura e se tornaram também mais baratos (CETRE, 2002, p. 26-27). Na França, antes mesmo de meados no século XIX, editores como Marescq, Gosselin et Garnier Fréres chegaram a vender romances em fascículos, com boa qualidade material, mas a preços elevados. Outros, no entanto, preferiram publicar romances a baixo preço, mas com frágil qualidade tipográfica. Esse foi o caso do editor Paulin em 1833, de Curmer em 1838, seguidos, em diferentes momentos, por Bry, Havard, Barba, Fayard, Hetzel, Dentu, Marpon et Flamarion, Tallandier, etc (Ibidem, p. 27).

Como se percebe, a origem da venda de obras em fascículos não esteve, desde os seus primórdios, diretamente ligada ao gênero romance. Contudo, ao se apropriar dele e vazá-lo nesse suporte, possibilitou fazer concorrência ao romance folhetim, que também comercializava ficção de forma fracionada. No caso do romance vendido em fascículos, a vantagem residia no fato de o leitor poder encaderná-los ao final da publicação de forma a constituir um livro no formato códex.

A fórmula foi, ao que tudo indica, um sucesso editorial, ultrapassando as fronteiras da França e Inglaterra. Não por acaso é possível encontrar editores e tipógrafos portugueses empenhados no lançamento de coleções de romances cujos exemplares eram comercializados em fascículos mediante a assinatura do leitor. Neste caso, tratou-se não apenas de vendê-los aos pedaços, mas também de fazê-lo no interior de uma coleção, ou seja, de um projeto editorial planejado de antemão.

Revista Moara, n. 52, jan-jul 2019 ISSN: 0104-0944

Recebido em 10/04/2019

Avaliado em 09/05/2019 
Tendo isto em vista, pretende-se discutir aspectos da publicação de romances em fascículos no interior de coleções criadas por agentes editoriais do Oitocentos português. Para tanto serão utilizados os paratextos editoriais de exemplares de prosa de ficção francesa disponíveis no Grêmio Literário Português do Pará, gabinete de leitura fundado em 1867 na Província do Pará.

Muito embora habitualmente pensemos o universo da publicação de livros como resultado da ação de editoras, no século XIX português nem sempre essa era a norma. Não raro, iniciativas editoriais eram tomadas por outros agentes do mundo do livro que tomavam para si múltiplas tarefas. Esse foi o caso do tipógrafo Joaquim Nery, que criou a coleção "Romances de Paul de Kock". Nery traduzia os romances do autor francês e ele mesmo se ocupava de imprimi-los em sua própria tipografia, a Tipographia Neryana, localizada em Lisboa, na Rua da Prata, 17. Graças a um posfácio, denominado "Invocação aos Senhores Assignantes" e publicado nas páginas finais do $4^{\circ}$ e último volume do romance João, de Paul de Kock, é possível tomar conhecimento da modalidade de circulação dos exemplares da coleção, assim como das estratégias publicitárias utilizadas pelo tipógrafo com vistas a garantir o sucesso de seu empreendimento. Vejamos, pois, como isso se dava, explorando o posfácio anteriormente referido. Ao leitor porventura desavisado, o tradutor/editor procura explicar que o romance cuja publicação fora finalizada, assim como o próximo a ser lançado, faziam parte de uma coleção cuja confiabilidade seria comprovada por sua duração, já que completava seis anos de vida:

\footnotetext{
É concluído o romance JOÃO, e certamente conta o tradutor que muito deve ter agradado.

Seis anos acaba de completar esta publicação, e mais hum está a ser encetado, e o tradutor, sempre confiando no favor dos seus Assinantes, vai apresentar em seguida:

FRERE JACQUES (irmão Thiago) (KOCK, 1846)
}

Após o anúncio do título da futura publicação, Joaquim Nery apresenta ao leitor a síntese do enredo. Frère Jacques (Irmão Thiago), explica, narra a história de dois irmãos. Um deles teria sido pervertido pela paixão jogo, seduzido pela criminalidade e, por consequência, desonrado; e o outro, a despeito de ter abandonado muito precocemente a casa paterna, mantivera intactos os princípios da honra. Dito isto, o Revista Moara, n. 52, jan-jul 2019 ISSN: 0104-0944 Recebido em 10/04/2019 
tradutor sugere as razões pelas quais a leitura desse romance poderia ser interessante. Além de servir de lição ao leitor, certamente o divertiria dada a comicidade da narrativa que, conforme sugere, seria familiar aos conhecedores de Paul de Kock. ${ }^{1}$ Por fim, faz crer que nos idos da década de 1840 já interessava aos leitores constituir sua própria biblioteca por meio da assinatura de sua coleção:

Tal é o romance que o tradutor vai oferecer aos seus assinantes, contando que, posto serem as circunstancias em que atualmente nos achamos, pouco favoráveis a todos em geral, ainda assim, continuando na sua bondade auxiliadora para com o tradutor, não deixarão de aumentar a sua coleção com o belo romance. (Ibidem)

Interessa notar como o editor se dirige ao leitor e o que isso revela dessa modalidade de publicação. Joaquim Nery se refere à "bondade auxiliadora" desse leitor, do qual depende a sobrevivência de sua coleção. Não se trata da compra de um livro em formato códex, cujo volume pode ser vendido em uma livraria não requerendo nenhum tipo de engajamento do leitor a longo prazo. No caso das coleções de romances vendidos em fascículos, o leitor, como se percebe, atua como uma espécie de sócio do editor, uma vez que, ao assinar a coleção, garante os recursos necessários à publicação das obras que dela fazem parte.

Resta saber como se davam as regras de adesão a esse tipo de projeto editorial. No caso da coleção de Joaquim Nery não há informações a esse respeito nos paratextos editoriais dos exemplares disponíveis. No entanto, é possível discutir essa problemática em outras coleções editoriais, como a "Bibliotheca Popular", criada por S.C.. Na última página do $2^{\circ}$ volume da edição de Os companheiros da morte, romance publicado em 1864 e vertido livremente para a língua portuguesa por J. A. Xavier de Magalhães, temse a explicação acerca do modus operandi do editor no que diz respeito ao sistema de vendas por assinatura. $\mathrm{O}$ editor anuncia a publicação de $O$ rei da Itália, obra a ser lançada após o término de Os Companheiros da Morte e, em lugar de apresentar o resumo do enredo, como o fizera Nery, ou mesmo de tecer extensas considerações sobre as vantagens da leitura da obra, apenas afirma se tratar de um romance histórico

\footnotetext{
${ }^{1}$ Sobre a comicidade dos romances de Paul de Kock cf: PANTOJA, 2013.
}

Revista Moara, n. 52, jan-jul 2019 ISSN: 0104-0944

Recebido em 10/04/2019

Avaliado em 09/05/2019 
interessantíssimo, cuja qualidade não necessitaria ser atestada, já que inserido no conjunto maior da coleção:

\begin{abstract}
É este interessantíssimo romance histórico, que tencionamos publicar, logo que houvermos concluído a publicação de Os companheiros da morte. Não tecemos elogios a essa obra; os nossos leitores sabem já por experiencia, quanto nos esmeramos na escolha dos romances que mandamos traduzir, portanto julgamo-los desnecessários. (CASTILLE, 1864)
\end{abstract}

Nota-se, assim como se dá no caso da coleção de Nery, como o leitor está diretamente implicado na publicação das obras. Essa implicatura, no entanto, deve extrapolar a publicação de um titulo em particular; deve, necessariamente, ter o caráter de um engajamento a longo prazo, capaz de garantir a vida da coleção. Esta, como se percebe, depende da capacidade de o editor agradar a esse leitor que pode, a qualquer momento, deixá-lo na mão, inviabilizando seu negócio. Nesse sentido, a duração das coleções de romances publicadas em fascículos servem, em grande medida, como pistas sobre as preferências de parcelas do público leitor dessa época, uma vez que sua duração depende diretamente das graças desse público. Por outro lado, depende também de uma justa equação que tem como variáveis o preço a ser pago e a qualidade do material a ser entregue. Não por acaso, ao anunciar o próximo lançamento de sua coleção, Sales enfatiza o fato de o próximo volume ser impresso com tipos novos e papel de superior qualidade:

\begin{abstract}
As condições das assinaturas são as mesmas das obras já publicadas: 20 réis por cada folha de 16 páginas (in $8^{\circ}$ ). O typo será novo e o papel de superior qualidade. Depois da obra completa, aumentará de preço na proporção de 25 por cento do que custar aos srs. assinantes. $O$ solicitador de 8 assinaturas realizáveis terá uma grátis. Assina-se em todas as lojas de livros do costume e na tipografia de Salles, largo de S. Domingos, n. 17, 3o andar, aonde toda a correspondência deve ser dirigida franca de porte. (Ibidem)
\end{abstract}

Essas informações talvez só possam ser compreendidas em sua plenitude quando o leitor do século XXI manuseia um desses livros. O papel fino, quebradiço, semelhante a um jornal velho, a tinta preta esmaecida, a parca marginália, o corte descuidado da folha a ponto de suprimir o número da página, não deixam dúvidas sobre as razões pelas quais o editor da "Biblioteca Popular" tentava convencer os leitores das melhorias a serem empreendidas na próxima publicação.

Revista Moara, n. 52, jan-jul 2019 ISSN: 0104-0944 Recebido em 10/04/2019 Avaliado em 09/05/2019 
No entanto, é preciso ter em vista a relação direta entre o barateamento do livro no século XIX e a qualidade do material que lhe servia de suporte. No caso dos romances vendidos em fascículos, deve-se considerar também que a modalidade de publicação tem impacto significativo sobre o preço do livro: o leitor, na condição de cofinanciador da obra, uma espécie de sócio do editor, paga por ela um valor inferior àquele que pagará o não assinante, como se evidencia no posfácio acima citado. Ainda assim, parece que esses artifícios poderiam não ser suficientes para manter a fidelidade do leitor, caso contrário o editor não ofereceria outras vantagens para além da redução de $25 \%$ sobre o preço final do livro. Prova disso reside no fato de Sales oferecer uma obra grátis a cada oito assinaturas como recompensa à fidelidade do leitor.

Essa estratégia comercial não lhe era exclusiva, pelo contrário. U.P. de Castro Telles, editor da "Bibliotheca Romântica", também se valeu desse recurso para agradar aos assinantes de sua coleção. No posfácio do $2^{\circ}$ volume do romance Cinq-Mars, de Alfred de Vigny, agradece o acolhimento do leitor e oferece, como prova de reconhecimento, a distribuição mensal e gratuita de uma "notícia de modas e vestuário de último gosto". (VIGNY, 1843) Explica também que as obras publicadas pela biblioteca serão impressas e distribuídas semanalmente, em folhetos, custando 40 réis cada um deles. As estampas, por sua vez, também custarão 40 réis cada. Contrariamente ao editor S. C. da "Bibliotheca Popular", Castro Telles não esclarece a quantidade de páginas e o formato dos folhetos a serem entregues ao leitor. Contudo, se preocupa em garantir a confiabilidade de seu negócio, afirmando ser bem conhecido por não ter faltado às condições expressas em seus prospectos:

\footnotetext{
O editor, já bem conhecido por ter publicado até hoje aos folhetos oito volumes sem ter faltado a algumas das condições dos seus prospectos, espera que tantos os senhores de Lisboa, como os das Províncias, que o tem coadjuvado até o presente, o continuarão a ajudar não só com as suas assinaturas, mas até com a dos seus amigos. (Ibidem)
}

Pode-se ler tais considerações a contrapelo, ou seja, supor que o rompimento do “contrato" estabelecido entre editor e leitor também pudesse ser violado pelo primeiro, seja interrompendo a publicação, seja entregando um produto cuja materialidade não correspondesse àquela que ficara acordada no momento da assinatura. Muito Revista Moara, n. 52, jan-jul 2019 ISSN: 0104-0944 
provavelmente tenha sido por essa razão que Castro Telles garante nunca ter vendido "gato por lebre". O tempo de vida de sua coleção ${ }^{2}$ certamente dependia desse fino e frágil equilíbrio resultante do atendimento às expectativas do leitor. A busca por esse equilíbrio não era, certamente, esforço exclusivo desse editor, pois do ajuste a essas expectativas dependia o sucesso ou fracasso dessas coleções editoriais.

Ao que tudo indica, algumas dessas coleções chegaram a ter uma vida relativamente longa, como foi o caso da "Bibliotheca das Damas". Em um "Aviso aos Leitores" publicado no romance $O$ Aventureiros ou $O$ Barba Azul, de Eugène Sue, o editor revela que a coleção estava prestes a completar três anos de vida, o que ocorreria com o lançamento do $40^{\circ}$ romance. Atribuía o sucesso da coleção ao devido cumprimento dos compromissos assumidos com os assinantes:

\begin{abstract}
Com o número 40, que deve sair por todo o mês de maio próximo, principia o terceiro ano da BIBLIOTHECA DAS DAMAS. O bom acolhimento que tem tido os romances publicados nos primeiros dois anos da Bibliotheca, são uma prova de que o editor não faltou aos compromissos que se impôs com os Illmos srs. assinantes, que tanto o tem coadjuvado nesta publicação, pelo que se confessa eternamente agradecido. A Bibliotheca vai, pois, iniciar o terceiro ano da sua existência com um lindo e interessante romance de Eugenio Sue Os filhos do Amor - que ainda não foi vertido no nosso idioma. Os Filhos do Amor serão publicados em três números. (SUE, 1854)
\end{abstract}

Lourenço de Sousa, editor e proprietário da tipografia em que fazia imprimir a referida coleção, anuncia que além dos romances franceses, pretendia publicar alguns originais portugueses. Pode-se supor, portanto, que o sucesso do empreendimento, já com três anos de duração, fizera crer ao editor que os romances escritos por seus conterrâneos também seriam bem aceitos pelas damas portuguesas. No que diz respeito à distribuição das obras, informa que seria realizada de quinze em quinze dias, com exemplares de 96 páginas, ao custo de 120 réis pagos no ato da entrega. Aos novos assinantes cuja coleção estava incompleta, explica que faria imprimir os números esgotados, sem modificação de preços, de forma a lhes garantir a possibilidade de tê-la por inteiro.

\footnotetext{
${ }^{2}$ Sabemos que até aquele momento o editor havia publicado 8 títulos, mas não é possível saber quanto tempo foi necessário para publicá-los em fascículos.
}

Revista Moara, n. 52, jan-jul 2019 ISSN: 0104-0944

Recebido em 10/04/2019 Avaliado em 09/05/2019 
Como se pode notar, todos esses empreendimentos editoriais procuravam encontrar uma forma de distribuição cuja periodicidade e pagamento em parcelas possibilitasse tornar o livro acessível ao leitor. Além disso, procuravam fidelizar este último por meio de um sem número de estratégias comerciais, que incluíam o oferecimento de prêmios e vantagens, a redução do preço para aqueles que faziam as assinaturas e a oferta de exemplares gratuitos para os que aderiam a mais de uma publicação. Por certo o preço constituía elemento fundamental na garantia dessa fidelização, caso contrário os editores não teriam tanto cuidado em divulgá-lo em cada uma das publicações.

\section{Considerações finais}

O uso do termo "popular", do "povo" ou "para todos", que acompanha o título de várias dessas coleções, é um indicativo da intenção de franquear o acesso mais amplo ao objeto livro. Muito embora por vezes o termo "romance popular" seja utilizado para designar certas obras, certamente nenhuma delas pode ser denominada popular, se o suporte material e o acesso decorrente da sua forma de publicação não o for. Salvo nesse sentido, constitui equívoco utilizar o termo, uma vez que qualquer obra, independente de suas origens, somente se torna popular em decorrência de uma série de operações editoriais que garantem sua ampla circulação.

O termo "edição popular", que pode ser aplicado a diversas obras publicadas no interior dessas coleções editoriais, diz respeito não apenas à modalidade de publicação, como assinalamos anteriormente, mas também a certas características do suporte material, responsáveis por tornar viável o barateamento do produto. Ainda que essas coleções vendidas em fascículos não fossem idênticas, grande parte delas apresentava características materiais similares: papel de pouca qualidade, fonte miúda, espaço reduzido entre as linhas, marginália quase inexistente, poucas ilustrações, geralmente localizadas no verso do olho ou distribuídas parcimoniosamente ao longo da obra. Não resta dúvida de que os próprios exemplares dessas coleções eram o locus privilegiado de comunicação com o leitor, uma vez que os paratextos editoriais informavam as 
condições de assinatura, bem como quais seriam os próximos lançamentos.

Dessa forma, o objeto livro se tornava ao mesmo tempo veículo de um texto literário e de outro publicitário, o que garantia o estabelecimento de um laço entre a obra então publicada e a que viria a seguir, constituindo uma cadeia no interior da qual o leitor era peça fundamental.

Finalmente, é importante enfatizar que, tal qual ocorria com o leitor de romancefolhetim, os assinantes dessas publicações aceitavam o pacto da leitura seccionada e interrompida. $\mathrm{Na}$ impossibilidade de comprar o volume de uma só vez, pagavam-no em prestações, recebendo em troca fascículos que podiam ser reunidos e encadernados ao final da publicação. O sonho de uma biblioteca privada se tornava possível até mesmo àqueles que não possuíam renda suficiente para entrar em uma livraria e dela sair com um volume em mãos.

Da perspectiva do editor, a publicação em fascículos garantia a existência de seu negócio sem que fosse necessário empreender grandes aportes de capital, pois o leitor se tornava um parceiro no financiamento do projeto editorial. Por consequência, era possível aferir a boa ou má recepção da obra em tempo real, pois se o leitor abandonasse a assinatura no meio do caminho, significava que não havia agradado. Tratava-se, assim, de um negócio arriscado, mas que, se bem conduzido, evitava catástrofes maiores, como o encalhe de obras publicadas de uma só vez em formato códex.

Do ponto de vista da história do livro e da leitura, a pesquisa sobre a modalidade de venda de romances em fascículos tem grande relevância porque é um testemunho das práticas históricas de barateamento do livro, que tem como resultado a democratização de seu acesso ao público leitor. De outro lado, lança um desafio aos estudiosos da literatura, que via de regra costumam ignorar os suportes materiais pelos quais as obras são dadas a ler, assim como as modalidades de publicação por meio das quais circulam. Se os pesquisadores da literatura pretendem compreender o que liam seus antepassados, ampliando seu interesse para além das obras consagradas pelos historiadores da literatura, certamente terão que voltar seus olhos para o mercado editorial e suas 
dinâmicas, pois, sem dúvida alguma, os escritores escrevem textos, mas quem garante sua circulação são os agentes editoriais, responsáveis por encarná-los em suportes materiais portadores de historicidade.

\section{REFERÊNCIAS}

CASTILLE, Hyppolyte. Os companheiros da morte. Lisboa: Typographia de Salles, vol. 2 (sic), 1864.

CETRE, Natalie. L'édition en fascicules de romans français entre 1870 et 1914 et leur conservation. Mémoire d'Etude. Ecole Nationale Supérieure des Sciences de l'Information et des Bibliothèques. Paris: 2002.

DICTIONNAIRE ENCYCLOPEDIQUE DU LIVRE. Pascal Fourché, Daniel Péchoin, Philippe Schuwer (dir). Paris: Electre-éditions du Cercle de la Librairie. Tomo II, 2005. KOCK, Paul de. João. Lisboa: Tipographia Neryana, vol. 4, 1846.

PANTOJA, Alessandra. Das imagens de si ao mundo das edições: Paul deZKock, romancista popular. Dissertação (Mestrado em Letras). Universidade Federal do Pará. Belém, 2013.

SUE, Eugenio. O aventureiro Barba Azul. Porto: Typ. de J. Lourenço de Sousa, vol. 1, 1854.

VIGNY, Alfredo Victor. Cinq-Mars ou Uma conjuração no reinado de Luiz XIII: romance histórico (enriquecido com anotações históricas). Lisboa: A. U. P. de Castro Telles, vol.2, 1843.

Revista Moara, n. 52, jan-jul 2019 ISSN: 0104-0944

Recebido em 10/04/2019 Avaliado em 09/05/2019 